\title{
Analyses of the 16S-23S intergenic region of the phytoplasma causing the sugarcane white leaf disease in Yunnan Province, China
}

\author{
Xiao-Yan Wang¹, Wen-Feng Li ${ }^{1}$, Ying-Kun Huang ${ }^{1 *}$, Rong-Yue Zhang ${ }^{1}$, Zhi-Ming Luo ${ }^{1}$, Hong-Li Shan', Jiong Yin ${ }^{1}$, \\ Ke Shen ${ }^{1}$, Ying-Ming $\mathrm{Jia}^{2} \&$ Zhi-Gang Bai ${ }^{2}$
}

${ }^{1}$ Sugarcane Research Institute, Yunnan Academy of Agricultural Science, Yunnan Key Laboratory of Sugarcane Genetic Improvement, Kaiyuan 661699, P. R. China; ${ }^{2}$ Baoshan Sugarcane Research Institute, Tongren Street No. 114, Longyang District, Baoshan 678000, P. R. China

Author for correspondence: Ying-Kun Huang, e-mail: huangyk64@163.com

\begin{abstract}
Sugarcane white leaf (SCWL) is an important disease caused by a phytoplasma. In Baoshan, Yunnan, China, SCWL was firstly observed in 2012, and has extended its area of occurrence to $600 \mathrm{hm}^{2}$. Up to $52 \%$ of the plants may become diseased in a field and even complete loss of cane yield may result in the heavily infected fields, posing a serious threat to Yunnan sugar industry. To ascertain the causal agent of suspected SCWL disease in Yunnan, nested PCR using two sets of phytoplasma primer pairs (MOLX/MLOY and P1/ P2) was used to successfully amplify a genomic region of the $16 \mathrm{~S}$ ribosomal DNA (16S rDNA) from 36 suspected SCWL samples. On the basis of sequencing, phylogenetic analysis and nucleotide alignments of 17 nested PCR products randomly selected from positive samples, identical fragments of $210 \mathrm{bp}$ in length were obtained that could be clustered into the 6Sr group XI (Rice Yellow Dwarf group) and shared $100 \%$ identity with the $16 \mathrm{~S}-23 \mathrm{~S}$ intergenic spacer region (ISR) of a member of this group, the SCWL phytoplasma (GenBank: HQ917068), and 99.52\% with Sugarcane grassy shoot phytoplasma, of the same group. These results indicate that the SCWL disease in Baoshan is caused by a phytoplasma of the 6Sr group XI.
\end{abstract}

Key words: Saccharum, disease detection, etiology, nested PCR.

Sugarcane white leaf (SCWL) disease, caused by a phytoplasma, is one of the most important diseases of sugarcane (Nakashima et al., 1994; Wongkaew et al., 1997; Hanboonsong et al., 2002; Wongkaew \& Fletcher, 2004; Hanboonsong et al., 2006). SCWL was first observed in Lumpang province in the northern part of Thailand in 1954 (Marcone, 2002), and was reported in Taiwan in 1958 (Ling, 1962). At present, SCWL is known from India, Sri Lanka, Laos, and Myanmar (Kumarasinghe \& Jones, 2001; Rao et al., 2005; Thein et al., 2012). SCWL causes severe losses, reducing the number of millable canes in the planted crop, and the disease severity can increase in the ratoon crop. In Thailand, a 5\%-35\% disease incidence for SCWL has been recorded, resulting in losses to sugarcane farmers amounting to US\$20 million every year (Hanboonsong et al., 2006). With 100\% losses in the cultivar 'Ragna' in New Guinea, SCWL was responsible for considerable economic losses for the local sugar industry (Rao et al., 2005).

Phytoplasmas have been reported to be associated with two major sugarcane diseases, SCWL and SCGS. SCWL is characterised by leaf chlorosis and white striations. Diseased leaves are smaller and narrower than uninfected leaves, and have a soft texture. Plants with SCGS are dwarfed and develop witches' broom-type symptoms by producing a large number of tillers (Chona et al. 1960; Sarosh, 1986; Rishi \& Chen, 1989). SCWL phytoplasma is naturally transmitted by the leafhopper Matsumuratettix hiroglyphicus (Matsumura) and Yamatotettix flavovittatus (Hanboonsong et al., 2002; Hanboonsong et al., 2006), but the insect vector responsible for the natural spread of SCGS has not yet been identified

Based on electron microscopic observation, SCWL has been previously detected in some cultivars that were grown in Fujian Province, Nanning (Guangxi Province), and Kaiyuan (Yunnan Province) in China in 1987 (Zhou et al., 1987), but it has not been reported in China for the past 20 years. In 2012, suspected SCWL symptoms were observed on plants in Baoshan, Yunnan, China. The present study aimed at identifying the causal agent of suspected SCWL disease. Phytoplasmas were originally detected by electron microscopy and serological assays (Viswanathan, 1997), but these methods do not allow for pathogen identification, and are not always sufficiently sensitive to detect phytoplasma infections because phytoplasmas are usually unevenly distributed and are present in low titres in plant tissues. Molecular methods are a more reliable for phytoplasma identification and are superior in their versatility, relative simplicity, specificity, and high sensitivity. To increase the 
Analyses of the 16S-23S intergenic region of the phytoplasma causing the sugarcane...

sensitivity of the PCR assay, researchers often use nested PCR (Andersen et al., 1998; Lee et al., 1994). A nested polymerase chain reaction (PCR)-based method was hence used for the confirmation of the etiology of this sugarcane disease.

In October of 2012, 36 sugarcane leaf samples from varieties PY3120, Yunzhe86-61, Yunzhe03-194, Yuetang86-368, and Yuetang93-159 with suspected SCWL symptoms were collected from Shidian and Longyang of Baoshan City, Yunnan, China.

Total DNA was extracted from $0.2 \mathrm{~g}$ of each leaf sample using the improved CTAB extraction procedure described by Harrison et al. (1994). A DNA extracted from an infected sugarcane individual (cultivar UT3) was used as a positive control (provided by the Yunnan Key Laboratory of Sugarcane Genetic Improvement, Kaiyuan, China). The nested-PCR product of this positive control was sequenced The result of a BLAST search showed that it shared $100 \%$ sequence identity with the sequence from the Thailand SCWL phytoplasma (GenBank accession HQ917068) and over 99\% identity with isolates from India and Hawaii (GenBank accession DQ380345, JN223448). DNA extracted from phytoplasma-free healthy sugarcane plants was used as a negative control, and double distilled water was used as a blank control.

Nested PCR assays were carried out using primer pairs with sequences complementary to the 16S rDNA of the phytoplasmas (Hanboonsong et al., 2002). The first set consisted of primers MLOX (5'GTTAGGTTAAGTCCTAAAACGAGC-3') and MLOY (5'-GTGCCAAGGCATCCACTGTATGCC-3'), that amplify a $700 \mathrm{bp}$ DNA fragment. The second set of primers P1 (5'-GTCGTAACAAGGTATCCCTACCGG-3')/P2 (5'GGTGGGCCTAAATGGACTTGAACC-3') amplify a 210 bp fragment. The first PCR amplification was performed in a $20 \mu \mathrm{L}$ reaction mixture containing $1 \mu \mathrm{L}$ total DNA template, $2.5 \mu \mathrm{L} 10 \times \mathrm{PCR}$ buffer, $1 \mu \mathrm{L}$ each primer $(20 \mu \mathrm{mol} / \mathrm{L}), 0.5$ $\mu \mathrm{L} \mathrm{MgCl}_{2}(25 \mathrm{mmol} / \mathrm{L}), 1 \mu \mathrm{L}$ dNTPs $(10 \mathrm{mmol} / \mathrm{L}), 0.2 \mu \mathrm{L}$ Taq DNA polymerase $(5 \mathrm{U} / \mu \mathrm{L})$ and $12.8 \mu \mathrm{L} \mathrm{ddH}_{2} \mathrm{O}$. The reaction was heated to $94^{\circ} \mathrm{C}$ for $5 \mathrm{~min}$, followed by 25 cycles of denaturation for $1 \mathrm{~min}$ at $94^{\circ} \mathrm{C}$, annealing for $1 \mathrm{~min}$ at $55^{\circ} \mathrm{C}$, and extension for $1 \mathrm{~min}$ at $72^{\circ} \mathrm{C}$, with a final extension for $10 \mathrm{~min}$ at $72^{\circ} \mathrm{C}$. For nested PCR, $1 \mu \mathrm{L}$ of the first PCR product (diluted 1:100 in sterile deionized water) was used as template in the same reaction mixture as in the first PCR except for the primers; the amplification conditions were $5 \mathrm{~min}$ at $94^{\circ} \mathrm{C}$ followed by 35 cycles, each consisting of denaturation at $94^{\circ} \mathrm{C}$ for $1 \mathrm{~min}$, annealing at $62^{\circ} \mathrm{C}$ for $1 \mathrm{~min}$, and extension at $72^{\circ} \mathrm{C}$ for $1 \mathrm{~min}$, followed by extension for $10 \mathrm{~min}$ at $72^{\circ} \mathrm{C}$. The positive control, negative control and blank control were included. PCR products were analysed by electrophoresis through a $2 \%$ agarose gel in Tris-acetateEDTA (TAE) buffer, stained with ethidium bromide and visualized with a UV transilluminator.

Seventeen nested PCR products were randomly selected from positive samples, excised from the gel and purified using the TIANgel Midi Purification kit(TIANGEN, Beijing, China). DNA fragments were ligated into the plasmid vector pMD18-T (Takara, Dalian, China), and the recombinant plasmids were introduced into Escherichia coli strain DH5a (Sangon, Shanghai, China) by transformation. The six positive clones from each sample were selected and the inserts were sequenced at BGI Sequencing (Beijing) Co. Ltd. Next a BLAST search against the NCBI (http://www. ncbi.nlm.nih.gov) sequence databases, homology analysis was performed with DNAMAN, version 6.0. A phylogenetic tree was constructed using the neighbor-joining program as implemented in the genetic analysis software MEGA, version 4.0 (Tamura et al., 2007) with Acholeplasma brassicae (GenBank: AY974060) as the outgroup.

The suspected SCWL symptoms observed on sugarcane in Baoshan were similar to those described previously in sugarcane (Marcone, 2002; Wongkaew \& Fletcher, 2004). Disease started with leaves showing pale streaks and mottling and progresssed towards the entire leaves turning white. Younger leaves became infected first, and diseased plants showed white leaves in the spindle area, with the older leaves remaining green. The infected plants showed stunting, proliferating tillers, shortened internodes, and thin stalks (Figure 1).

Nested PCR products of approximately $200 \mathrm{bp}$ were amplified from DNA extracted from all 36 symptomatic SCWL tissue samples with primers MLOX/MLOY followed by $\mathrm{P} 1 / \mathrm{P} 2$, but no amplification product was obtained from the negative control DNA isolated from a healthy sugarcane plant or from double distilled water control (Figure 2).

Seventeen nested PCR products were randomly selected from positive samples, cloned and six clones from each sample were sequenced. The results showed that the sequences were all 210-bp in length and were all identical. One of these was deposited in GenBank under accession number KC662509. A BLAST search indicated that the sequence obtained in the present study (GenBank accession KC662509) shared 100\% nucleotide sequence identity with the $16 \mathrm{~S}-23 \mathrm{~S}$ intergenic spacer region (ISR) sequence from the SCWL phytoplasma from Thailand (GenBank accession HQ917068) and $99.52 \%$ with those of Sugarcane grassy shoot phytoplasma (Table 1).

A phylogenetic tree was constructed with $1916 \mathrm{~S}$ rDNA sequences from typical phytoplasmas of the $16 \mathrm{Sr}$ group. The resulting tree showed that the sequence identified in this study (GenBank accession KC662509) is closely related to that from the SCWL phytoplasma and also the sugarcane grassy shoot (SCGS) phytoplasma, which are members of the 16Sr XI group (Figure 3).

SCWL is among the most destructive of sugarcane diseases, causing severe losses to farmers who grow this important crop. The disease is easily spread over long distances by infected seedcane. In 2011, the suspected SCWL phytoplasma infected plants were initially scattered over an area of $5 \mathrm{hm}^{2}$ in the Shidian plantations in Baoshan, Yunnan, China. However, this soon expanded to $80 \mathrm{hm}^{2}$ and was also 

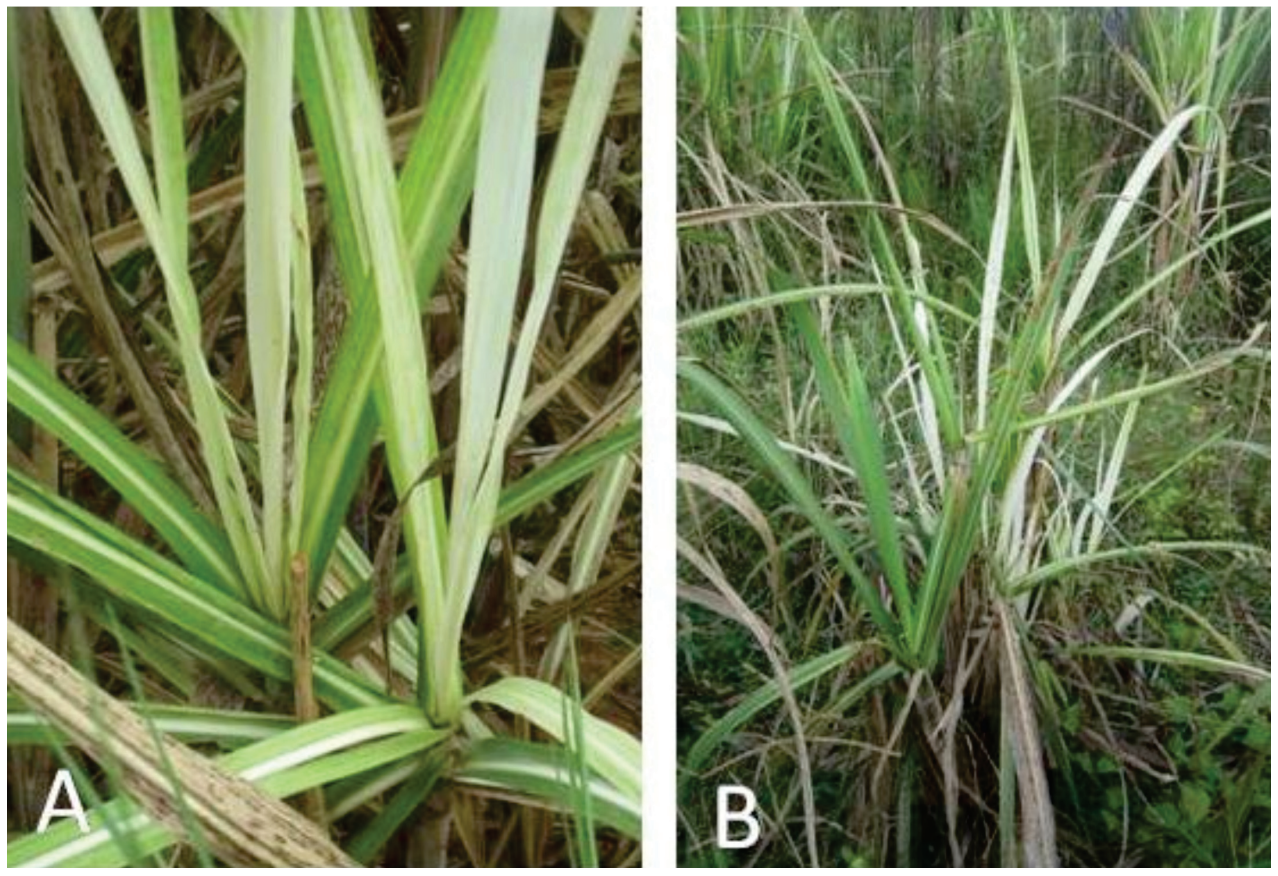

FIGURE 1 - Sugarcane infected with Sugarcane white leaf disease (SCWL) in Banshan, Yunnan, China. A. Infected leaves on plants at shooting stage. B. Infected plants at mature stage.

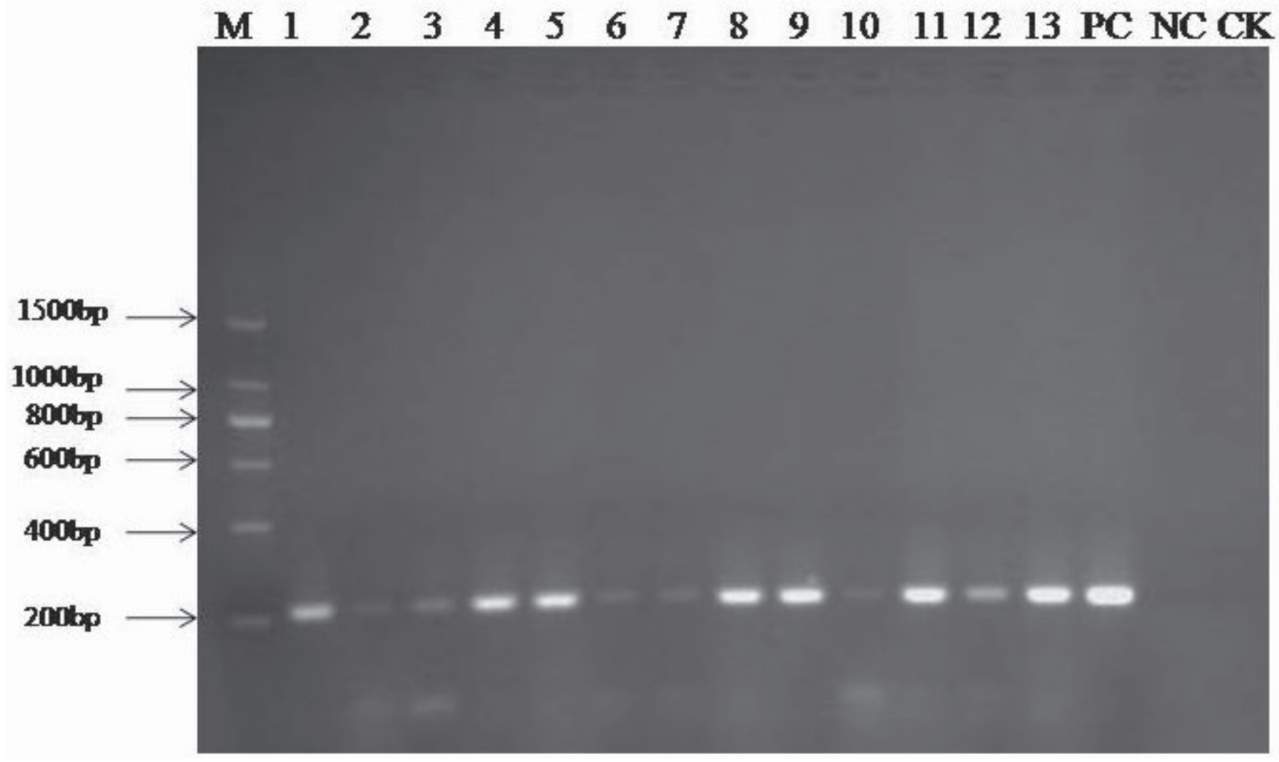

FIGURE 2 - Nested PCR amplification of phytoplasma 16S rDNA from plants suspected to be infected with SCWL collected from Baoshan, Yunnan, China. M, DNA Marker. 1-13, symptomatic samples collected from the SCWL-infected areas. PC, positive control. NC, negative control. CK, blank control.

observed sporadically in fields of Longyang in Baoshan, Yunnan, China in 2012. Confirmation of the etiology of diseases is critical for making effective management decisions to prevent the spread of SCWL and ensure the sustainable development of the sugar industry. In this study all 36 suspected SCWL samples were positive for the presence of the phytoplasm. Sequence comparison showed that the DNA sequence obtained in this study (GenBank accession KC662509) belonged to the phytoplasma $16 \mathrm{Sr}$ XI group, and shared $100 \%$ nucleotide identity with the 16S-23S ISR sequence from the SCWL phytoplasma originally from Thailand (GenBank: HQ917068). These results showed that the white leaf symptom in sugarcane plants in Baoshan, Yunnan, was caused by a phytoplasma, and further studies need to be done to identify the correct species of this phytoplasma. 
Analyses of the 16S-23S intergenic region of the phytoplasma causing the sugarcane...

TABLE 1 - Comparison of 16S rDNA nucleotide sequences from Baoshan SCWL isolate with other phytoplasmas of the 16Sr groups.

\begin{tabular}{lllc}
\hline \hline 16Sr & Associated phytoplasma & $\begin{array}{c}\text { GenBank } \\
\text { accession No. }\end{array}$ & $\begin{array}{c}\text { Homology (\%) } \\
\text { Broup }\end{array}$ \\
& & & $\begin{array}{c}\text { SCWL isolate } \\
\text { (GenBank } \\
\text { accession KC662509) }\end{array}$ \\
\hline I & Aster yellows & 76.62 \\
II & Faba bean phyllody & AY549311 \\
III & Grapevine yellows & EF193354 & 42.33 \\
IV & Coconut lethal decline & AF060875 & 43.64 \\
V & Elm yellows & U18753 & 44.39 \\
VI & Clover proliferation & FJ611961 & 43.50 \\
VII & Ash yellows & L33761 & 44.39 \\
VIII & Loofah witches'-broom & AF092209 & 85.24 \\
IX & Pigeon pea witches'-broom & AF248956 & 87.79 \\
X & Apple proliferation & L33735 & 44.64 \\
XI & Sugarcane white leaf & EF193361 & 46.64 \\
& Sugarcane white leaf & HQ917068 & 100 \\
& Sugarcane white leaf & JN223448 & 99.05 \\
& Sugarcane grassy shoot & JF754447 & 99.52 \\
& Sugarcane grassy shoot & GU138402 & 99.52 \\
XII & Sugarcane grassy shoot & JF754448 & 99.52 \\
XIII & Liquidambar yellows & JF754449 & 99.52 \\
XIV & Mexican periwinkle virescence & DQ660363 & 85.24 \\
XV & Bermuda grass white leaf & AF248960 & 84.29 \\
& Hibiscus witches'-broom & Y16388 & 38.89 \\
\hline
\end{tabular}

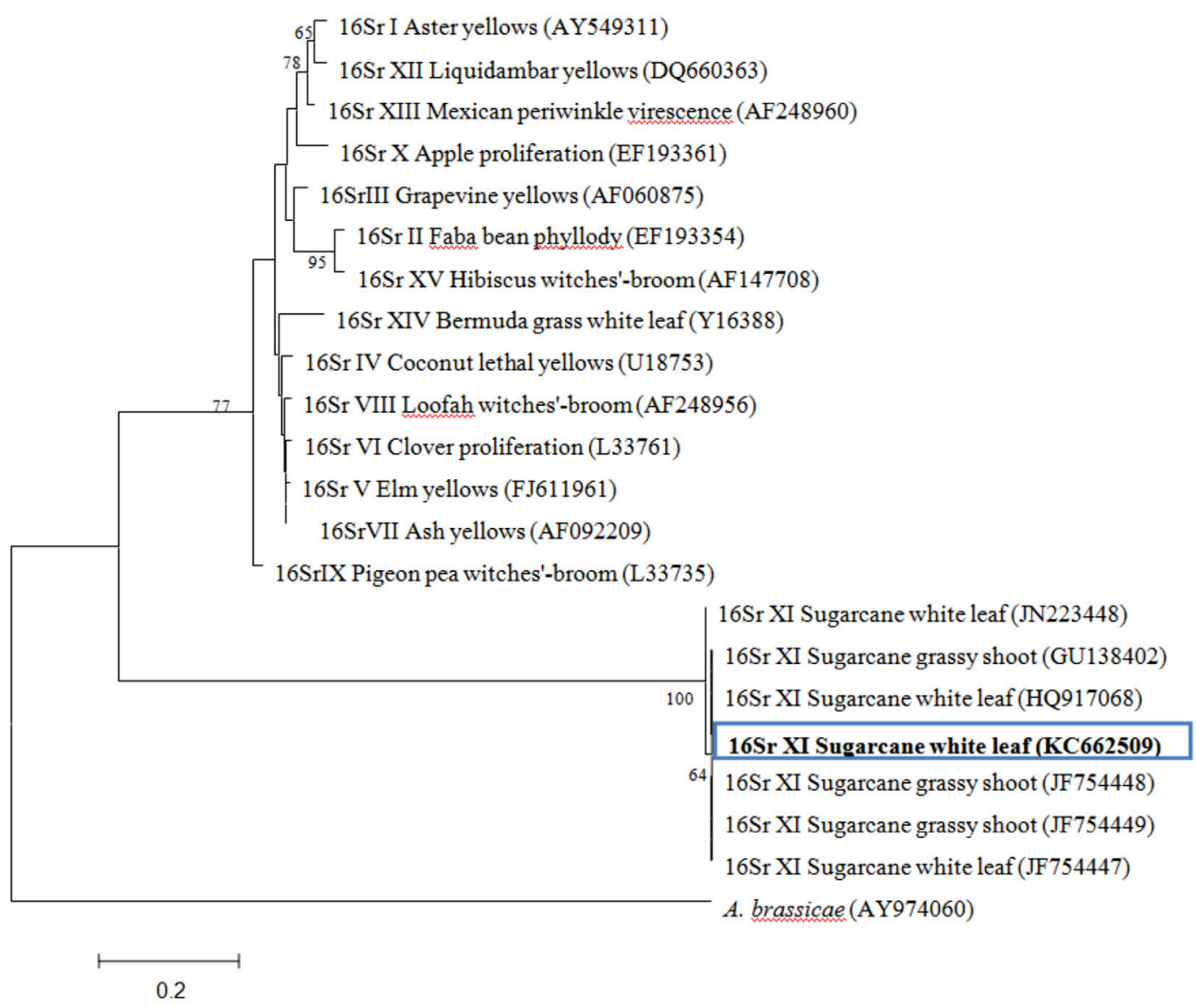

FIGURE 3 - Phylogenetic distance tree constructed by the neighbor-joining method, comparing the 16S rDNA sequence of the present study (sugarcane white leaf from Baoshan, Yunnan, China) with those of other representative phytoplasmas from GenBank. Acholeplasma brassicae was used as an outgroup species. Accession numbers are shown in parentheses. Numbers at branch nodes are bootstrap percentages (1,000 replicates). The sequence determined in this study was showed in the box. Bars representing genetic scale. 
The sequence comparison analysis performed here revealed that the $16 \mathrm{~S}-23 \mathrm{~S}$ ISR sequences from the phytoplasma identified in this study (GenBank accession KC662509) and the SCGS phytoplasma (GenBank: GU138402, JF754448, JF754449), which is also a member of the 16Sr XI group, shared $99.52 \%$ nucleotide identity, and there was no significant difference between SCWL phytoplasma and SCGS phytoplasma. The unequivocal identification at the species level this phytoplasma needs further in-depth studies.

Only part of the cane-growing areas in Baoshan City, Yunnan Province were monitored for SCWL in this study. This survey needs to be expanded. Also, in order to genereate a theoretical basis and technical support for the effective control of SCWL, further studies are needed to complete the experimental work for the detection of insect species which might be responsible for the transmission of SCWL in China, and a systematic and comprehensive study of the occurrence and field epidemic dynamics of SCWL in all cane-growing regions of China is also necessary.

\section{ACKNOWLEDGEMENTS}

This work was supported by grants from the Earmarked Fund for China Agriculture Research System (CARS-20-2-2) and the Earmarked Fund for Yunnan Province Agriculture Research System for project support.

\section{REFERENCES}

Andersen MT, Beever RE, Gilman AC, Liefting LW, Balmori E, Beck DL, Sutherland PW, Bryan GT, Gardner RC, Forster RLS (1998) Detection of Phormium yellow leaf phytoplasma in New Zealand flax (Phormium tenax) using nested PCRs. Plant Pathology 47:188-196.

Chona BL, Capoo SP, Varma PM, Seth ML (1960) Grassy shoot disease of sugarcane. Indian Phytopathology 13:37-47.

Hanboonsong Y, Choosai C, Panyim S, Damak S (2002) Transovarial transmission of sugarcane white leaf phytoplasma in the insect vector Matsumuratettix hiroglyphicus (Matsumura). Insect Molecular Biology 11:97-103.

Hanboonsong, Y., Ritthison, W., Choosai, C., \& Sirithorn, P. (2006). Transmission of sugarcane white leaf phytoplasma by Yamatotettix flavovittatus, a new leafhopper vector. Journal of Economic Entomology 99:1531-1537.

Harrison NA, Richardson PA, Jones P, Tymon AM, Eden-Green SJ., Mpunami AA (1994) Comparative investigation of MLOs associated with Caribbean and African Coconut lethal decline diseases by DNA hybridization and PCR assays. Plant Disease 78:507-511.

Kumarasinghe NC, Jones P (2001) Identification of white leaf disease of sugarcane in Sri Lanka. Sugar Tech 3:55-58.

Lee I-M, Gundersen DE, Hammond RW, Davis RE (1994) Use of mycoplasmalike organism (MLO) group-specific oligonucleotide primers for nested-PCR assays to detect mixed-infections in a single host plant. Phytopathology 84:559-566.

Ling KC (1962) White leaf disease of sugarcane. Taiwan Sugar 9:1-5.

Marcone C (2002) Phytoplasma disease of sugarcane. Sugar Tech 4:79-85.

Nakashima K, Chaleeprom W, Womgkaew P, Sirithorn P (1994) Detection of mycoplasma-like organisms associated with white leaf disease of sugarcane in Thailand using DNA probes. Japan International Research Center for Agricultural Sciences 1:57-67.

Rao GP, Singh A, Singh HB, Sharma SR (2005) Phytoplasma diseases of sugarcane: characterization, diagnosis and management. Indian Journal of Plant Pathology 23:1-21.

Rishi N, Chen CT (1989) Grassy shoot and white leaf disease. In: Ricaus BC, Egan BT (Eds.) Diseases of sugarcane. Amsterdam, The Netherlands. Elsevier Science. pp. 289-300.

Sarosh, Misra SR, Kishan-Singh, Singh K (1986) Anatomical studies on sugarcane affected with grassy shoot disease. Indian Phytopathology 39:499-502.

Tamura K, Dudley J, Nei M, Kumar S (2007) MEGA4: Molecular Evolutionary Genetics Analysis (MEGA) software version 4.0. Molecular Biology and Evolution 24:1596-1599.

Thein MM, Jamjanya T, Kobori Y, Hanboonsong Y (2012) Dispersal of leafhoppers Matsumuratettix hiroglyphicus and Yamatotettix flavovittatus (Homoptera: Cicadellidae), vectors of sugarcane white leaf disease. Applied Entomology and Zoology 47:255-262.

Viswanathan R (1997) Detection of phytoplasmas associated with grassy shoot disease of sugarcane by ELISA techniques. Journal of Plant Diseases and Protection 104:9-16.

Wongkaew P, Hanboonsong Y, Sirithorn P, Choosai C, Boonkrong S, Tinnangwattana T, Kitchareonpanya R, Damak S (1997) Differentitation of phytoplasmas associated with sugarcane and gramineous weed white leaf disease and sugarcane grassy shoot disease by RFLP and sequencing. Theoretical and Applied Genetics 95:660-663.

Wongkaew P, Fletcher J (2004) Sugarcane white leaf phytoplasma in tissue culture: long-term maintenance, transmission, and oxytetracycline remission. Plant Cell Reports 23:426-434.

Zhou ZJ, Lin QY, Xie LH (1987) Sugarcane white leaf disease occurrence and observation of its pathogens by electron microscopic. Journal of Fujian Agricultural College 16:165-168. 